\title{
Integrated Model towards Computer Assisted Language Learning Acceptance: Empirical Case Study of Saudi Universities
}

\author{
Abdul Fattah Soomro* \\ English Language Centre, Deanship of Supportive Studies, Taif University, Taif, Saudi Arabia \\ Corresponding author: Abdul Fattah Soomro, E-mail: soomroafatah@hotmail.com
}

\section{ARTICLE INFO}

Article history

Received: February 19, 2018

Accepted: April 14, 2018

Published: April 31, 2018

Volume: 6 Issue: 2

Conflicts of interest: None

Funding: None

\begin{abstract}
Maximum utilization of technology in all fields of life including language education by a country has become inevitable to survive in the competitive world. Saudi government has already invested a lot of efforts and public finance to adopt modern teaching practices using Information Communication Technology (ICT) to supplement English Language Teaching (ELT) in Saudi Arabia. The present study applies Technology Acceptance Model (TAM) as a theoretical model to explore the effects of different factors on the attitudes of teachers towards using ComputerAssisted Language Learning (CALL) in the language learning contexts of Saudi Arabia. The current study investigates the effect of perceived usefulness and perceived ease of use on the attitude and intended usage behavior of Saudi English as a Foreign Language (EFL) teachers towards using CALL. In addition to these two factors borrowed from TAM, three other variables: social influence, facilitating conditions and management support are added into the model. To test the hypothesized model, this study applied a quantitative questionnaire survey approach with participants chosen randomly from 10 different universities in Kingdom of Saudi Arabia. A total of 421 valid responses received through online questionnaire from the teachers were used for the analysis to achieve research objectives and hypotheses testing. Structural Equation Modeling Analysis was employed to analyze the data. The findings of this study are found very encouraging and provide sufficient support to the proposed model of the study, which was consisting of TAM as the foundation theory. According to TAM, postulation perceived usefulness and perceived ease of use both are two significant elements that determine attitude and intended usage behavior. These hypotheses were found significant, thus provided external validity to the TAM postulations. In addition, the findings suggested that social influence, management support, and facilitating conditions are important factors that influence individuals' intended behavior towards CALL usage.
\end{abstract}

Key words: Computer-assisted Language Learning (CALL), Technology Acceptance Model (TAM), Second Language Acquisition (SLA)

\section{INTRODUCTION}

The Information Communication Technology (ICT) has created scenarios and innovative paradigms for learning through both vertical (teacher to student) and horizontal (peer to peer) and communication and collaboration which have transformed the face of learning. The effect of ICT is evident in all fields of education as well as in language learning. Computer-Assisted Language Learning (CALL), in the field of language learning, has achieved much acknowledgement and assistance from students, instructors and educationists. Levy (1997) defines CALL as "the search for and study of applications of the computer in language teaching and learning" (p.1). Thus, CALL is an educational concept which is extensive as it includes its own methodology, pedagogy, and implementation. First time, CALL was introduced in the early sixties as a disseminator of information. It then soon became a significant factor for Second Language Acquisition (SLA) and English in particular. By the eighties, it developed as an established tool and was widely used with introduced features of multimedia as well as the concept of learning in communities and it has now gained recognition the world over for its success in supporting SLA (Lambropoulos, Christopoulou, \& Vlachos, 2006; He \& Ma, 2007). Although CALL offers a great alternative pedagogy for English as a Foreign Language (EFL) acquisition, this varies in each state of adoption due to its own peculiar environment and needs. The victorious enforcement of Information Communication Technology (ICT) into the educational sectors is not a common case of generating software and then installing hardware, appropriate attention must be paid to the elements for example pedagogy, societal culture, pedagogical culture and the particular persons. 


\section{Use of Technology in the EFL Contexts of KSA}

According to Khan (2011), to improve the standard of EFL, the government has planned to adopt modern teaching practices using ICT to supplement English Language Teaching (ELT) in Saudi Arabia. This use of ICT in Second Language Acquisition (SLA) is referred to as Computer Assisted Language Learning (CALL). Mahdi (2013) holds the view that the Saudi authorities provide a lot of educational institutions with essential hardware and software for CALL. Unfortunately, despite establishing programs like Tatweer (2008) to assimilate ICT in education; the incorporation of CALL in EFL in Saudi schools comes across many problems for example- lack of budget, training and skills, pedagogical information, motivation, negative behaviours, and a limited departmental as well as classroom culture (AlKahtani, 2007; Al-Rojaie, 2011; Khan, 2011; Soomro \& Almaki 2017).

Some scholars, while criticizing the conventional pedagogy, consider that omnipresent ICT in 'Net' generation of the present time has made it essential to incorporate it in education (Jones \& Cross, 2009). Moreover, the benefits of incorporating technology in the language learning are enumerable. However, the issue is not technological merely but pedagogical. As Price and Kirkwood (2008) posits it's very difficult to know why, how and when to use learning technology. Recently, some education experts have suggested that things will not improve if we just throw "technology" in our classrooms. They suggest adopting a more mediocre paradigm which must acknowledge the fact that the technology is not "an important part of the reply...but in real the platform" for renovating education in almost all aspects of subjects. Educators must think of moving from incorporating "technology for the technology's purpose" as a tool for self-learning towards creating a learner-centric system. Secondly, language teachers are suggested not simply using technology because it is available. Instead, they seek to make sure the pedagogic importance of whatever channel/ mode of instruction they decide to use.

In view of issues facing CALL use in different learning contexts of the world including Saudi Arabia, the literature suggests to approach the topic from change management and diffusion of innovation perspectives. The adoption of innovations, such as CALL in Saudi Arabia, could be well understood from the perspective of change management. Therefore, change theory is important to the discussion about the acceptance of CALL. Change theory has potential to inform as well as enable teachers and policy makers to develop better understanding of how innovations, such as CALL, are to be adopted in educational instruction. Fullan (1991) reports that instructions are difficult to be improved if people are not having a better understanding of the pedagogical change, reasoning and logic behind it, the advantages and benefits of it, and the ways of adopting it. Therefore, the misunderstanding is one of reasons why adopters of change become failure in making the most of such change programs. Consequently, understanding of change is very important for successful implementation of technology which could possibly be better understood via change theory. Change theory is capable of helping us to understand the challenges an inno- vation may confront when accepted in various contexts. The present study would help us to get useful understanding so that we may be able better integrate CALL in Saudi classrooms. There are widely accepted theories in this field to provide the most thorough elaboration of the change process related to the adoption of an innovation. The famous models which have been incorporated to create understanding regarding acceptability of innovation are Theory of Reasoned Action, Theory of Planned Behaviour, Diffusion of Innovation Theory, and Technology Acceptance Model.

\section{Technology Acceptance Model (TAM)}

TAM has achieved a tremendous help in understanding and controlling the process of new adaptation in the technology (Chen, Chen, Lin \& Yeh, 2007; Dillon \& Morris, 1996; Masrom, 2007; Park, 2009). TAM was first introduced by David in the year (1989) to be utilized in predicting or assuming user acceptance to any kind of information system. Further, to diagnose the problem of designing before the time a user in actual uses the system via two factors. These two factors are: perceived ease of use (PEU) and perceived usefulness (PU) (Dillon \& Morris, 1996; Chen et al., 2007). As in the views of Lee, Cho, Gay, Davidson \& Ingraffea (2003), the perceived usefulness is elaborated as "The degree to which a person believes that use of technology will produce better outcomes." This elaborates that the online learning benefits students and they could learn through online system and improve their progress (Yee, Luan, Ayub \& Mahmud, 2009). PEU elaborates the user's perception towards the particular amount of energy used by the student to learn through any technology or any student who believes that giving that much time will be effortless (Alrafi, 2009). In this research the PEU is actually a learner's perception regarding the time and effort used in learning.

The main idea of TAM use is actually user's acceptance of technology which is actually designed or constructed by a user's behavior and intention based on the learner's PU and PEU (Wu, 2009). Further, Behavioral intention (BI) is utilized to elaborate "the extent to which a student formulates conscious plans to use or not to use online learning related activities (Clement \& Bush, 2011; Li \& Huang, 2009; Ramayah \& Ignatius, 2005). BI is strongly related to the person's actual behavior; in other words: "if a person intends to do a behavior, then it is likely to be done." Likewise, TAM believes that users construct a positive attitude towards the conditions when he believes that that will be easy for him to use and operate (Lee et al., 2003). Depending on TAM, upper levels of PU and PEU predict feasible behaviors which, in return, predict the inclination to utilize (Lucas, 1997). One's actual use of a technology system is influenced directly or indirectly by the one's behavioral intentions, attitude, perceived usefulness of the system, and perceived ease to use the system (Park, 2009, p.151).

\section{Determinants of Students' Acceptance of Online Learning}

The research on e-learning involves the studies to influence the students' behavior and attitudes towards the acceptance 
or rejection of technology. The students' usage in technology would be better evident by knowing that how much the learners are better in using internet and engage autonomously in learning. The students' use of technology is an additional thing to learn on in their academic lives by creating an environment of online learning (Proffitt, 2008, p.18). Likewise, the learners' social influence on their referent groups and their behavior towards online learning are some additional subjects related to a person's attributes and they could affect their intentions to learn through internet. Similarly, the social effect of (Bertea, 2009; Shen, Laffey, Lin \& Huang, 2006) the users' practical utilization of the technology is highly affected by their behavioral motives, which is further affected by the user's previous experiences in the field of technology usage (Sumak, Hericko, Pusnik \& Polancic, 2011). However, the said features (learners' perceptions of beneficiary and easy to operate, attitudes and social impact variables) could make encourage students' acceptance and mood to use online technology for learning.

The present study applies TAM as a theoretical model to explore the effects of different factors on the attitudes of learners towards using CALL in the language learning contexts of Saudi Arabia. The current study investigates the effect of perceived usefulness and perceived ease of use on the attitude and intended usage behavior of Saudi EFL teachers and learners towards using CALL. In addition to these two factors borrowed from TAM, three other variables social influence, facilitating conditions and management support are added into the model. The model given below in Figure 1 seeks to determine the relation between different variables and the effect of all these on the attitude towards using CALL.

\section{Hypotheses of the Study}

H-1 Attitude will have important effect on Behavioral Intention towards using CALL.

H-2 Perceived usefulness will have important effect on Attitude towards using CALL.

H-3 Perceived Ease of Use will have significant impact on Perceived Usefulness.

H-4 Social factors will have significant effect on Attitude towards using CALL.

H-5 Facilitating Conditions will have significant effect on Attitude towards using CALL.

H-6 Management Support will have significant effect on Attitude towards using CALL.

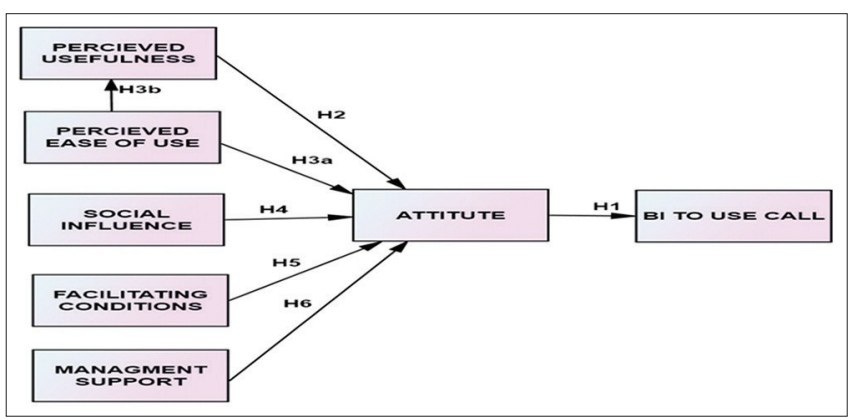

Figure 1. Conceptual framework developed by the researcher

\section{METHOD}

To test hypothesized model as depicted in Figure 1, this study applied a quantitative questionnaire survey approach with participants chosen randomly from 10 different universities in kingdom of Saudi Arabia. The survey instrument was designed based on the existing scales available in the literature. To minimize the potential biasness in sampling, authors chose to approach subjects at diverse locations (i.e. universities). The unit of analysis in this research were individual teachers using CALL. The online questionnaire was made available to the participants. Some of the questionnaires were incomplete so only 421 valid responses were used for the analysis to achieve the research objectives and hypotheses testing.

\section{Data Analysis}

\section{Preliminary analysis}

Missing values were dealt using Byrne's three stage approach. According to Byrne (2001), the important steps required to handle with the issue of missing data are, first to check the amount of missing data, second step deals with identifying the design of the missing data, and finally investigating the suitable techniques to fix the missing data. After analysis it was seen that the amount of missing data was less (i.e. $0.3 \%$ ) and the pattern was completely random. Kline (2011) and Hair, Ringle, and Sarstedt (2006) recommend that if missing data is spread in complete random manner, any suitable remedy can be adopted and would produce acceptable results. As a results, authors applied regression imputation to fix the missing values in data. This is also consistent with prior work (Chandio, Irani, Abbasi, \& Nizamani, 2013).

In order to deal with outliers, authors applied Mahanobis distance $\left(\mathrm{D}^{2}\right)$ statistical test. Although results suggest existence of few outliers in the data, following researchers' (Hair et al., 2006) recommendations it was however decided to retain those cases with outliers. This is so because there was not enough evidence that could suggest that these cases were not a segment of the whole population. In addition, to check the potential common method variance bias (CMV) in the data, Harman's method was employed (Podsakoff, MacKenzie, S. B., Lee, J. Y., \& Podsakoff, 2003). Main reason for assessing CMV was due to cross sectional nature of the study. Results revealed that only $11 \%$ value accounted in the general construct, which was lower than the threshold level (i.e. 50\%). Finally, although this research applied validated scales from extant literature to measure the CALL usage, it was however important to test the measurement items' internal consistency and reliability. Following prior work (Hair et al., 2006) this research applied Cronbach's Alpha measure to assess items' reliability. Results given in Table 1 suggest that all the values of alpha co-efficient were above the threshold value 0.7 , thus, indicating acceptable internal consistency of items. 


\section{Structural equation modeling analysis}

Structural equation modeling (SEM) is a collection of sophisticated statistical tests to deal with complex models. The main purpose of SEM is to facilitate researchers for testing relationships between multiple depended and independent variables simultaneously (Hair et al., 2006). As per researchers' (Anderson \& Gerbing, 1988; Hair et al., 2006; Kline, 2005) recommendations, SEM should be applied in two stages, which are estimation of structural model and as well as measurement model.

\section{Measurement model specification}

The measurement model (MM) was specified with interlinks between the observed variables (i.e. items) and unobserved variables (i.e. constructs). The main reason of MM was to investigate the extent to which items i.e. analysed variables are loaded to their unexpressed latent unobserved variables (Chin, 1998). Which then can be used to examine the convergent and discriminant validity of the construct. Conver-

Table 1. Instrument reliability

\begin{tabular}{llc}
\hline Constructs & Code & $\begin{array}{c}\text { Cronbach's } \\
\text { alpha }\end{array}$ \\
\hline Perceived usefulness & PU & 0.82 \\
Perceived ease of use & PEOU & 0.91 \\
Facilitating conditions & FC & 0.90 \\
Social Influence & SI & 0.88 \\
Management Support & MS & 0.87 \\
Attitude & ATT & 0.93 \\
Behavioural Intention & BI & 0.89 \\
\hline
\end{tabular}

gent validity is the extent to which items share proportion of difference in common. Whereas discriminant validity deals with the extent to which constructs are truly different from one another (Hair et al., 2006). Convergent and discriminant validity was assessed following Fornel and Larcker's (1981) criteria. They suggest that the average variance extracted (AVE) of each latent variable is equal or above 0.5 establishes convergent validity. Table 2 depicts that AVE of all construct is greater than 0.5 , thus, confirming the establishment of convergent validity. On the other hand, for discriminant validity (DV) Fornel and Larcker (1981) suggested that if square root of AVE of each construct is higher than the corresponding inter-construct correlation (ICC), then the DV is established. As depicted in Table 2 all the squared AVE are higher than their corresponding ICC estimates, thus, confirming DV of all constructs.

\section{Structural model specification}

Structural Model (SM) was specified to test the hypotheses proposed in the study. SM basically represents the relationships between endogenous (commonly known as dependent variables) and exogenous (i.e. independent) variables. The results of SM and estimates, (i.e. critical ratio and $\beta$ values) are presented in Table 3 . These results suggest that all the hypotheses proposed in the model were significant at various levels. The highly significant correlation was found between PEOU and PU with critical ratio (CR) value 7.836 at significance level of $p<0.001$. Followed by PEOU and Attitude (i.e. $\mathrm{CR}=4.352$ ), Attitude and Behavioral intention $(\mathrm{CR}=4.091)$, Management support and Behavioral Intention $(\mathrm{CR}=3.839)$, and $\mathrm{PU}$ and Attitude $(\mathrm{CR}=3.627)$, respectively at $\mathrm{p}<0.001$ significance level. The significance level of rela-

Table 2. Measurement Model Estimates

\begin{tabular}{|c|c|c|c|c|c|c|c|c|}
\hline Constructs & AVE & BI & $\mathbf{P U}$ & PEOU & MS & SI & FC & ATT \\
\hline BI & 0.778 & 0.882 & & & & & & \\
\hline PU & 0.700 & 0.226 & 0.837 & & & & & \\
\hline PEOU & 0.624 & 0.209 & 0.426 & 0.790 & & & & \\
\hline MS & 0.709 & 0.295 & 0.285 & 0.235 & 0.842 & & & \\
\hline SI & 0.685 & 0.323 & 0.339 & 0.405 & 0.231 & 0.828 & & \\
\hline $\mathrm{FC}$ & 0.518 & 0.272 & 0.189 & 0.298 & 0.171 & 0.385 & 0.719 & \\
\hline ATT & 0.569 & 0.334 & 0.343 & 0.361 & 0.210 & 0.307 & 0.228 & 0.755 \\
\hline
\end{tabular}

Bold values are squared AVE, Off Diagonal values are inter-construct correlations

Table 3. Structural Model Estimates

\begin{tabular}{|c|c|c|c|c|c|c|}
\hline Constructs & Relationship & Constructs & Estimate & S.E. & C.R. & $\mathbf{P}$ \\
\hline$\overline{\mathrm{PU}}$ & $\begin{array}{l}<-- \\
\end{array}$ & PEOU & 0.609 & 0.078 & 7.836 & $* * *$ \\
\hline ATT & $<---$ & PU & 0.121 & 0.033 & 3.627 & $* * *$ \\
\hline ATT & $<---$ & PEOU & 0.209 & 0.048 & 4.352 & $* * *$ \\
\hline BI & $<---$ & ATT & 0.32 & 0.078 & 4.091 & $* * *$ \\
\hline BI & $<---$ & MS & 0.223 & 0.058 & 3.839 & $* * *$ \\
\hline BI & $<---$ & SI & 0.257 & 0.086 & 3.003 & 0.003 \\
\hline BI & $<---$ & $\mathrm{FC}$ & 0.153 & 0.069 & 2.21 & 0.027 \\
\hline
\end{tabular}


tionship between social influence and behavioral intention was at $\mathrm{p}<0.01$, while for Facilitating conditions and behavioral intention it was $\mathrm{p}<0.05$.

\section{DISCUSSION AND CONCLUSION}

The findings of this study are very encouraging and provide sufficient support to the proposed model of the study, which was consisting of TAM as foundation theory. According to TAM, postulation perceived usefulness and perceived ease of use both are two significant elements that determine attitude and intended usage behavior. These hypotheses were found significant in our work also, thus provided external validity to the TAM postulations. In addition to that our work also suggested that social influence, management support and facilitating conditions are important factors that influence individuals intended behavior towards CALL usage.

The findings obtained from this study possess a lot of theoretical as well as practical implications for researcher and practitioner (e.g. educationists, policy makers). From a theoretical perspective, this research initially tried to provide a detailed and systematic mechanism of understanding users' (teachers and leaners) attitude and intended CALL usage behavior by incorporating various factors from social psychology and information systems domain. The success of incorporation of these factors in TAM theory is evident from the finding obtained of this research. Results suggested that proposed model after incorporation of those factors exhibited a significant explanatory and predictive power. The significance of all hypothesized paths makes our extended model theoretically appealing and empirically validated.

From practical perspective, the key benefit of our work is that policy makers and top management now have a systematic way of examining their CALL system and investigating reliability about the impact of each factor on CALL usage through a proposed causal chain. All this will not only help the top management in task prioritization and resources allocation, but also will help policy makers to devise appropriate strategies focusing on important influential factors for better educational outcome through the application of CALL.

As mentioned earlier, the main purpose of the study was to know the effect of various factors on the attitude of teachers towards CALL. The study found that all the variables had a direct and significant effect on teachers' attitudes towards CALL. The result of the study are consistent with the theoretical arguments made by Davis (1989) and past studies in which TAM was examined (Masrom, 2007; Teo et al., 2007). In the light of the results of the study, it's recommended that teachers be trained well so that they could be able to use computers with CALL applications without much difficulties. In addition, they may also be convinced that CALL is very useful in their learning and teaching context and can bear good results in terms of learning outcome among their EFL students. The availability of resources also play important role. The results showed a significant relation between facilitating conditions and teachers' attitude. So, it is very important to provide essential facilities. The role of manage- ment in providing helping hand and offering incentives plus developing good working environment is very crucial in the utilization of CALL by the teachers in the EFL context of Saudi Arabia. In addition, the universities in Saudi Arabia may take measures to encourage teachers for integrating more computer technology into their teaching and curriculum design. In this way, they would believe and prefer using CALL-based approaches to teach instead of relying on the traditional ones. That could be possible only if Saudi teachers get familiar with CALL applications and software and feel at ease while using it.

It is noteworthy to mention here that although the main purpose of this research is obtained and however, findings of the study are motivating and useful in nature, this study also holds some limitations like most of the other surveys do. For example, the survey approach applied in this research was cross-sectional in nature. Although this is consistent with prior studies, it is suggested that future research should apply longitudinal approach for data collection to investigate the factors that have an influence on continuing CALL usage behavior.

\section{REFERENCES}

AlKahtani, S. (2007). CALL integration: A proposal for in-service CALL training program for EFL faculty at Saudi Arabian Universities. College of Language \& Translation Research Center, 42, 1-16.

Alrafi, A. (2009).Technology Acceptance Model. In: A. Alrafi (Ed.) Information Systems Adoption: A study of the technology acceptance model (pp.1-12). Manchester: VDM Verlag.

Al-Rojaie, Y. I. (2011, Nov). Saudi EFL Reading Teachers' Pedagogical Beliefs and Practices: A Qualitative Case Study. Journal of Arabic and Human Sciences, 5(1), $1-19$.

Anderson, J. C., \& Gerbing, D. W. (1988). Structural equation modeling in practice: A review and recommended two-step approach. Psychological bulletin, 103(3), 411.

Amaratunga, D., Haigh, R., Sarshar, M., \& Baldry, D. (2002). Assessment of facilities management process capability: A NHS facilities case study. International Journal of Health, 15(6), 277-288.

Bertea, P. (2009). Measuring students' attitudes towards e-learning: A case study. Paper presented at the $5^{\text {th }}$ international science Conference eLearning and Software for Education, Bucharest, Romania.

Byrne, M. M. (2001). Linking philosophy, methodology, and methods in qualitative research. AORN journal, 73(1), 207-210.

Bryman, A., \& Bell, E. (2011). Business Research Methods ( $3^{\text {rd }}$ ed.). USA: Oxford University Press.

Creswell, J. W., \& PlanoClark, V. L. (2011). Designing and conducting mixed methods research ( $2^{\text {nd }}$ ed.). London: Sage.

Chandio, F., Irani, Z., Abbasi, M. S., \& Nizamani, H. A. (2013). Acceptance of online banking information systems: an empirical case in a developing economy. Behaviour \& Information Technology, 32(7), 668-680. 
Chen, Y., Chen, C., Lin, Y. \& Yeh, R. (2007). Predicting College Student' Use of E-Learning Systems: An attempt to extend technology acceptance model. Retrieved [April January, 2018] from http://aisel.aisnet.org/pacis2007/121

Chin, W. W. (1998). The partial least squares approach to structural equation modeling. Modern methods for business research, 295(2), 295-336.

Clements, J. A. \& Bush, A. A. (2011, March 25-26). Habitual is use and continuance. Proceedings of the Southern Association for Information Systems Conference, Atlanta, GA, US.

Davis, F. D. (1993). User acceptance of information technology: System characteristics, user perceptions, and behavioural impacts. International Journal of Man- Machine Studies, 38(3), 475-487.

Davis, F. D. (1989). Perceived usefulness, perceived ease of use, and user acceptance of information technology. MIS Quarterly, 13(3), 319-340.

Dillon, A., \& Morris, M. G. (1996). User acceptance of information technology: Theories and models. Annual Review of Information Science and Technology, 31, 3-32.

Easterby-Smith, M., Thorpe, R., \& Lowe, L. (2003). Management Research: An Introduction. London: Sage.

Fornell, C., \& Larcker, D. F. (1981). Structural equation models with unobservable variables and measurement error: Algebra and statistics. Journal of Marketing Research, 18 (1), 39-50.

Fullan, M. G. (1991). The meaning of educational change. In M. G. Fullan, The new meaning of educational change (pp. 30-46). New York: Teachers College Press.

Gall, M. D., Gall, J. P., \& Borg, W. R. (2003). Educational Research: An introduction ( $7^{\text {th }}$ ed.). Boston, MA: Allyn and Bacon.

Hair, J. F., Ringle, C. M., \& Sarstedt, M. (2012). Partial least squares: the better approach to structural equation modeling? Long Range Planning 45 (6), 312-319He, G., \& Ma, L. (2007). On the Shifting Orientation of CALL towards Post-modernity. Foreign Language Education, 1(1).

Jones, C., \& Cross, S. (2009). Is there a net generation coming to university? In: ALT-C 2009 "In Dreams Begins Responsibility”: Choice, Evidence and Change, 8-10 September 2009, Manchester, UK.

Khan, I. A. (2011). Learning difficulties in English: Diagnosis and pedagogy in Saudi Arabia. Educational Research, 2(7), 1248-1257.

Lambropoulos, Christopoulou, \& Vlachos. (2006). Culture-Based Language Learning Objects: A CALL Approach for a Ubiquitous World. In P. Zaphiris, \& G. Zacharia, User-Centered Computer Aided Language Learning (pp. 22-40). Hershey, PA Idea Group.

Lee, J. S., Cho, H., Gay, G., Davidson, B. \& Ingraffea, A. (2003). Technology acceptance and social networking in distance learning. Educational Technology \& Society, $6(2), 50-61$.
Li, Y. \& Huang, J. (2009). Applying theory of perceived risk and technology acceptance model in the online shopping channel. World Academy of Science, Engineering and Technology, 53(1), 919-925.Levy, M. (1997). Computer assisted language learning: Context and conceptualization. Oxford: Clarendon Press.

Lucas, H. C. (1997). Technology acceptance and performance: A field study of Broker workstations. Center for digital economy research, Stern School Business, working paper.

Mahdi, H. S. (2013). Issues of Computer Assisted Language Learning Normalization in EFL Contexts. International Journal of Linguistics, 5(1), 191-203.

Masrom, M. (2007, May 21-24). Technology acceptance model and e-learning. Paper presented at the $12^{\text {th }}$ International Conference on Education, Sultan Hassanal Bolkiah Institute of Education, Universiti Brunei Darussalam.

Neuman, W. L. (2011). Social Research Methods: Qualitative and Quantitative Approaches. USA: Allyn and Bacon.

Park, S. Y. (2009). An analysis of the technology acceptance model in understanding university students' behavioral intention to use e-learning. Educational Technology \& Society, vol. 12, No. 3, 150-162

Podsakoff, P. M., MacKenzie, S. B., Lee, J. Y., \& Podsakoff, N. P. (2003). Common method biases in behavioral research: A critical review of the literature and recommended remedies. Journal of applied psychology, 88(5), 879.

Price, L., \& Kirkwood, A. (2008). Technology in the United Kingdom's higher education context. In S. Scott, \& K. Dixon (Eds.), The 21 $1^{\text {st }}$ Century, Globalised University: Trends and Development in Teaching and Learning (pp. 83-113). Perth: Black Swan.

Proffitt, L.N. (2008). A study of the influence of learner readiness on academic success and student perceptions of online learning. A dissertation presented in partial fulfilment of the requirements for the degree Doctor of Philosophy, Capella University.

Ramayah, T. \& Ignatius, J. (2005). Impact of perceived usefulness, perceived ease of use and perceived enjoyment on intention to shop online. Journal of Systems Management, vol. 3, No. 3, 36-51.

Shen, D., Laffey, J., Lin, Y. \& Huang, X. (2006). Social influence for perceived usefulness and ease-of-use of course delivery systems. Journal of Interactive Online Learning, vol. 5, No. 3, Winter. Retrieved [May 12, 2017] from http://www.ncolr.org/jiol/issues/PDF/5.3.4.pdf

Soomro, A. F., \& Almalki, M. S. (2017). Language Practitioners' Reflections on Method-Based and Post-Method Pedagogies. English Language Teaching, 10(5), 234242. https://doi.org/10.5539/elt.v10n5p234.

Sumak, B., Hericko, M., Pusnik, M. \& Polancic,G. (2011). Factors affecting acceptance and use of Moodle: An empirical study based on TAM. Informatica, vol. 35, 91-100.

Tashakkori, A., \& Teddlie, C. (2003). Handbook of mixed methods in social and behavioral research. London: Sage. 
Tatweer. (2008). Retrieved Feb 12, 2014, from King Abdul- Yee, H. T. K., Luan, W. S., Ayub, A. F. \& Mahmud, R. (2009). A relah Project for General Education Development: http:// www.tatweer.edu.sa/Pages/home.aspx view of the literature: determinants of online learning among students. European Journal of Social Sciences, 8(2), 246-252. 